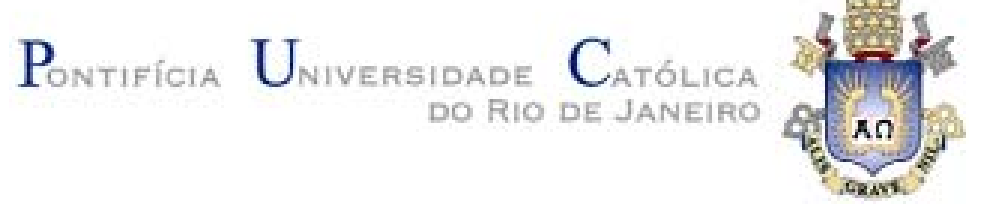

Flora Prata Machado

\title{
Aluno do PEJ: quem é você, Por onde você andou?
}

Dissertação de Mestrado

Dissertação apresentada como requisito parcial para obtenção do grau de Mestre em Educação pelo Programa de Pós-graduação em Educação do Departamento de Educação da PUC-Rio.

Orientador: Prof. Alícia Bonamino

Rio de Janeiro

Abril de 2004 


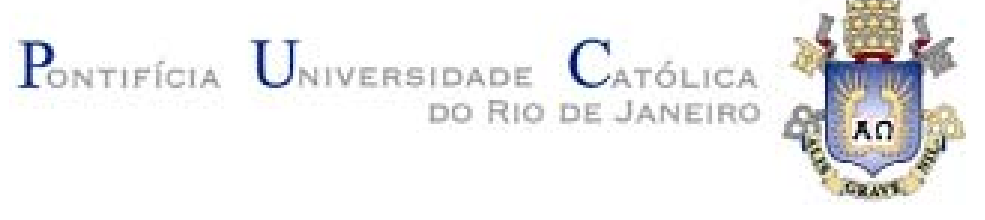

Flora Prata Machado

\title{
Aluno do PEJ: quem é você, Por onde você andou?
}

Dissertação apresentada como requisito parcial para obtenção do grau de Mestre pelo Programa de Pós-graduação em Educação do Departamento de Educação do Centro de Teologia e Ciências Humanas da PUC-Rio. Aprovada pela Comissão Examinadora abaixo assinada.

\author{
Prof. Alicia Bonamino \\ Orientador \\ Departamento de Educação - PUC-Rio \\ Prof. Creso Franco \\ Departamento de Educação - PUC-Rio
}

Prof. Jailson de Souza e Silva UFF

Prof. Paulo Fernando C. de Andrade Coordenador Setorial do Centro de Teologia e Ciências Humanas 
Todos os direitos reservados. É proibida a reprodução total ou parcial do trabalho sem a autorização da universidade, da autora e da orientadora.

\section{Flora Prata Machado}

Flora Prata Machado graduou-se em Pedagogia, em 1987, pela Universidade Federal Fluminense (UFF). É professora da Rede Pública Municipal do Rio de Janeiro desde 1985 tendo trabalhado, até o ano 2000, no Centro Integrado de Educação Pública - CIEP - Ministro Gustavo Capanema, no Bairro da Maré, ocupando diferentes funções: professora regente do ensino regular e da educação de jovens e adultos, professora de sala de leitura, diretora-adjunta, diretora e coordenadora pedagógica. Desde 2001 trabalha no Departamento Geral de Educação da SME Rio como Supervisora do Programa de Jovens e Adultos.

Ficha Catalográfica

Machado, Flora Prata

Aluno do PEJ : quem é você, por onde você andou? / Flora Prata Machado ; orientadora: Alícia Bonamino. - Rio de Janeiro : PUC, Departamento de Educação, 2004.

132 f. : il. ; $30 \mathrm{~cm}$

Dissertação (mestrado) - Pontifícia Universidade Católica do Rio de Janeiro, Departamento de Educação.

Inclui referências bibliográficas.

1. Educação - Teses. 2. Educação de jovens e adultos. 3. Fracasso escolar. 4. Trajetória escolar. 5. Estudo-piloto. 6. Classes populares. I. Bonamino, Alícia. II. Pontifícia Universidade Católica do Rio de Janeiro. Departamento de Educação. III. Título. 


\section{Agradecimentos}

Ainda que eu falasse as línguas dos homens e dos anjos, e não tivesse o amor, seria como o metal que soa ou como o sino que tine.

E ainda que tivesse o Dom da profecia, e conhecesse todos os mistérios e toda a ciência, e ainda que tivesse toda fé, de maneira tal que transportasse os montes, e não tivesse amor, nada seria.

E ainda que distribuísse toda a minha fortuna para sustento dos pobres, e ainda que entregasse o meu corpo para ser queimado, e não tivesse amor, nada disso me aproveitaria.

O amor é sofredor, é benigno; o amor não é invejoso; o amor não trata com leviandade, não se ensoberbece. Não se porta com indecência, não busca os seus interesses, não se irrita, não suspeita mal.

Não folga com a injustiça, mas folga com a verdade.

Tudo sofre, tudo crê, tudo espera, tudo suporta.

O amor nunca falha; mas havendo profecias, serão aniquiladas; havendo línguas, cessarão; havendo ciência, desaparecerá. Porque, em parte, conhecemos, e em parte, profetizamos. Mas, quando vier o que é perfeito, então o que o é, em parte, será aniquilado.

Quando eu era menino, falava como menino, sentia como menino, discorria como menino, mas logo que cheguei a ser homem, acabei com as coisas do menino. Porque agora vemos por espelho em enigma, mas então veremos face a face; agora conheço em parte, mas então conhecerei, como também sou conhecido.

Agora, pois, permanecem a fé, a esperança e o amor, estes três, mas o maior deles é o amor.

(I Coríntios, capítulo 13)

Amar e acima de tudo ser amada, incondicionalmente, por meu querido companheiro Fred, por minha orientadora Alícia, por meus amigos e colegas de trabalho, foi a condição que me permitiu concluir esse estudo.

Agradeço a todos que me incentivaram, "quebraram meus galhos", compreenderam minha ausência em muitos momentos importantes, me ensinaram e apontaram os melhores caminhos. A vocês, todo o meu carinho. 


\section{Resumo}

Machado, Flora Prata; Bonamino, Alícia. Aluno do PEJ: quem é você, por onde você andou? Rio de Janeiro, 2004. 132 p. Dissertação de Mestrado Departamento de Educação, Pontifícia Universidade Católica do Rio de Janeiro.

Esta pesquisa teve como objetivo desenhar um estudo contextual voltado para o conhecimento do perfil sociodemográfico e cultural e das trajetórias escolares dos alunos matriculados na educação de jovens e adultos, especificamente no Projeto de Educação Juvenil - PEJ, da Secretaria Municipal de Educação do Rio de Janeiro.

Trata-se de um estudo-piloto, ou seja, de uma versão em menor escala de um estudo completo, cujo objetivo foi testar aspectos do desenho da pesquisa, tais como o questionário e a amostra de alunos matriculados no PEJ em 2003, os procedimentos de coleta e a preparação da base de dados e a variância nas respostas, compreendendo, desta forma, as etapas inerentes a um survey.

A dissertação aborda detalhadamente essas etapas e seus produtos e apresenta considerações preliminares sobre as dimensões sociodemográfica, socioeconômica e cultural e sobre as trajetórias escolares dos alunos matriculados no programa, a partir da análise dos dados quantitativos coletados.

\section{Palavras-chave}

Educação de jovens e adultos; fracasso escolar; trajetória escolar; estudo-piloto; classes populares. 


\section{Abstract}

Machado, Flora Prata; Bonamino, Alícia (Advisor). The student of the PEJ: who are you, where do you come from? Rio de Janeiro, 2004. 132p. MSc. Dissertation - Departamento de Educação, Pontifícia Universidade Católica do Rio de Janeiro.

The principal objective of this research was to design a contextual study aimed at discovering the sociodemographic and cultural profile, as well as the school trajectories, of the students registered in the youth education project (Projeto de Educação Juvenil - PEJ) of the Municipal Secretariat of Education, Rio de Janeiro.

The research constitutes a pilot study, that is, a small scale version of a complete study, whose objective was to test aspects of the research design, such as the questionnaire and the sample of students registered in the PEJ in 2003, the processes of data collection, preparation of the data base and the variation of responses, comprehending the inherent stages of a survey.

The dissertation details these stages and their products, based on the quantitative data collected, presenting preliminary considerations on the sociodemographic, socio-economic and cultural dimensions, as well as the school trajectories, of the students registered in the project.

\section{Keywords}

Rural education, teacher education. 


\section{SUMÁRIO}

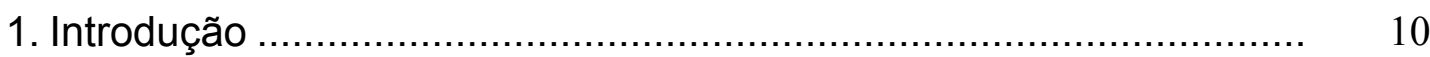

2. A constituição de uma trajetória profissional................................... 13

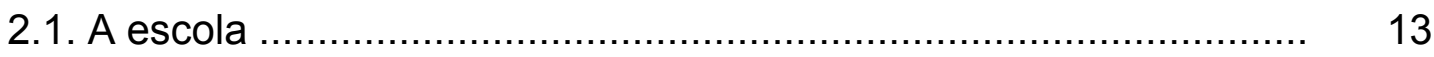

2.2. A organização social ........................................................... 16

2.3. Instância da administração pública ............................................... 18

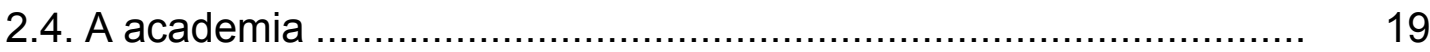

3. Caminhos na construção do tema da pesquisa ................................ 22

3.1. Conhecendo o PEJ .......................................................... 23

3.2. Conhecendo o tema da pesquisa ............................................ 24

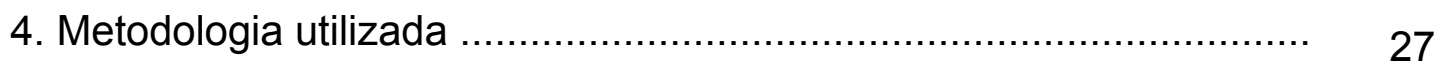

4.1. A seleção da amostra ........................................................... 28

4.2. Processo de construção do questionário ..................................... 30

4.2.1. Visita à literatura de referência do questionário ......................... 31

4.2.2. Realização dos pré-testes .................................................... 36

4.2.3. Apresentação do questionário final ...................................... 42

4.3. Aplicação dos questionários ................................................ 43

4.4. A importância dos alunos ausentes ......................................... 46

4.5. Elaboração do banco de dados .................................................. 49

5. Pontos provisórios de chegada da pesquisa .................................... $\quad 50$

5.1. Aluno do PEJ, quem é você? …….......................................... 50

5.1.1. Caracterização sociodemográfica ............................................ 50

5.1.2. Indicadores de renda e inserção no mundo do trabalho ............. 56

5.1.3. Experiências culturais, sociais e práticas de leitura ..................... 60

5.2. Por onde você andou? ........................................................... 65

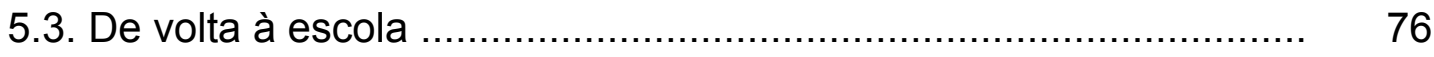

6. Considerações finais ............................................................... 82

6.1. Avaliação do estudo-piloto realizado ………………………....... 83

6.2. Algumas descobertas da pesquisa .......................................... 88

7. Referências Bibliográficas ………………………………........... 96

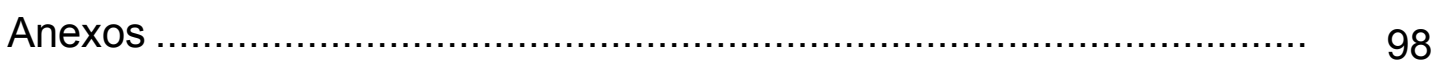

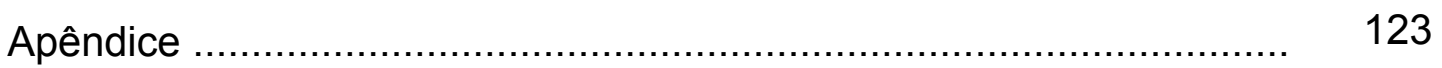




\section{Lista de figuras}

Gráfico 1 - Número de filhos por gênero do declarante .................... 55

Gráfico 2 - Relação entre a posse de carteira assinada e a cor declarada ........................................................ 59

Gráfico 3 - Existência de reprovações na vida escolar por grupo etário ............................................................ 71

Gráfico 4 - Se o aluno pretende continuar estudando ...................... 81

\section{Quadros e Tabelas}

Quadro 1 - PEJ - Crescimento das matrículas no PEJ de 1995 a

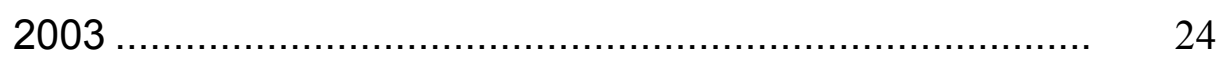

Quadro 2 - Relação das escolas que participaram da amostra ......... 28

Quadro 3 - Referência conceitual ............................................ 35

Quadro 4 - Percentual total de alunos ausentes por escola ............... 47

Quadro 5 - Tempo de matrícula do PEJ do aluno ausente ................. 48

Quadro 6 - Gênero dos alunos ausentes .................................. 48

Quadro 7 - Naturalidade dos alunos ausentes ............................... 48

Tabela 1 - Relação entre o gênero dos alunos e grupo etário ............. 51

Tabela 2 - Relação entre o PEJ de matrícula e o grupo etário ............. 53

Tabela 3 - Renda familiar bruta ................................................... 56

Tabela 4 - Relação entre o gênero do aluno e sua inserção no mercado de trabalho .............................................. 57

Tabela 5 - Motivos pelos quais o aluno não trabalha atualmente ........ 57

Tabela 6 - Relação entre a posse de carteira assinada e o grupo etário ..................................................................... 59

Tabela 7 - Relação entre experiências de acesso à Internet e PEJ de Matrícula ..................................................................... 64

Tabela 8 - Percentual de alunos que estudaram antes de ingressar no PEJ

Tabela 9 - Relação entre os motivos que impediram o aluno de estudar e seu gênero 
Tabela 10 - Relação entre a idade de ingresso na escola e a

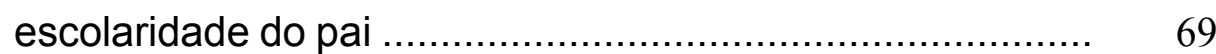

Tabela 11 - Existência de reprovações na trajetória escolar ................. 70

Tabela 12 - Relação entre a última série cursada e o PEJ de matrícula do aluno ....................................................... 72

Tabela13 - Relação entre a última série cursada e o início da escolaridade

Tabela 14 - Relação entre a última série cursada e experiências de Reprovação

Tabela 15 - Relação entre a última série cursada e a existência de interrupções na trajetória escolar ...................................... 75

Tabela 16 - Motivos que estimularam o aluno a voltar a estudar ......... $\quad 77$

Tabela 17 - Avaliação do PEJ ........................................................

Tabela 18 - Relação entre o que o aluno mais gosta no PEJ e seu PEJ de matrícula 